\title{
Oxidative damages in erythrocytes of patients with metabolic syndrome
}

\author{
A. Ziobro $\cdot$ P. Duchnowicz $\cdot$ A. Mulik $\cdot$ \\ M. Koter-Michalak $\cdot$ M. Broncel
}

Received: 14 December 2012/ Accepted: 2 March 2013/Published online: 21 March 2013

(C) The Author(s) 2013. This article is published with open access at Springerlink.com

\begin{abstract}
The aim of the study was to estimate the changes caused by oxidative stress in structure and function of membrane of erythrocytes from patients with metabolic syndrome (MS). The study involved 85 patients with MS before pharmacological treatment and 75 healthy volunteers as a control group. Cholesterol level, lipid peroxidation, glutathione level (GSH), and antioxidant enzyme activities in erythrocytes were investigated. The damage to erythrocyte proteins was also indicated by means of activity of ATPase (total and $\mathrm{Na}^{+}, \mathrm{K}^{+}$ATPase) and thiol group level. The membrane fluidity of erythrocytes was estimated by the fluorescent method. The cholesterol concentration and the level of lipid peroxidation were significantly higher, whereas the concentration of proteins thiol groups decreased in the patient group. ATPase and GSH peroxidase activities diminished compared to those in the control group. There were no differences in either catalase or superoxide dismutase activities. The membrane fluidity was lower in erythrocytes from patients with MS than in the ones from control group. These results show changes in red blood cells of patients with MS as a consequence of a higher concentration of cholesterol in the membrane and an increased oxidative stress.
\end{abstract}

A. Ziobro · P. Duchnowicz · A. Mulik ·

M. Koter-Michalak ( $\square)$

Department of Environment Pollution Biophysics, Faculty of Biology and Environmental Protection, University of Lodz, 141/143 Pomorska St., 90-237 Lodz, Poland

e-mail: koterm@biol.uni.lodz.pl

M. Broncel

Department of Internal Diseases and Clinical Pharmacology, Medical University of Lodz, 1/3 Kniaziewicza St., 91-347 Lodz, Poland
Keywords Metabolic syndrome $\cdot$ Erythrocyte $\cdot$ Oxidative damage $\cdot$ Cholesterol $\cdot$ Antioxidant enzymes · Glutathione · Lipid peroxidation

$\begin{array}{ll}\text { Abbreviations } \\ \text { MS } & \text { Metabolic syndrome } \\ \text { LDL } & \text { Low-density lipoprotein } \\ \text { HDL } & \text { High-density lipoprotein } \\ \text { TBA } & \text { Thiobarbituric acid } \\ \text { TBARS } & \text { Thiobarbituric acid reactive species } \\ \text { SOD } & \text { Superoxide dismutase } \\ \text { CAT } & \text { Catalase } \\ \text { GPx } & \text { Glutathione peroxidase } \\ \text { ROS } & \text { Reactive oxygen species } \\ \text { GSH } & \text { Reduced glutathione } \\ \text { GSSG } & \text { Oxidized glutathione }\end{array}$

\section{Introduction}

The metabolic syndrome (MS) was identified as a multiplex risk factor for cardiovascular disease which is one of the major causes of death. Overweight or obesity, abnormal lipid metabolism, hypertension, and insulin resistance are the major contributors in MS.

According to the International Diabetes Federation (IDF) new definition, a diagnosis of MS can be made when a person has central obesity (waist circumference $>94 \mathrm{~cm}$ for Europid men and $>80 \mathrm{~cm}$ for Europid women) and two out of four additional factors are present: raised triglyceride level $\geq 150 \mathrm{mg} / \mathrm{dL}$ or specific treatment for this lipid abnormality, reduced HDL cholesterol level $<40 \mathrm{mg} / \mathrm{dL}$ for men and $<50 \mathrm{mg} / \mathrm{dL}$ for women or specific treatment for this lipid abnormality, raised blood pressure (systolic $\geq 130 \mathrm{~mm} \mathrm{Hg}$ or 
diastolic $\geq 85 \mathrm{~mm} \mathrm{Hg}$ ) or treatment of previously diagnosed hypertension and raised fasting plasma glucose $\geq 100 \mathrm{mg} / \mathrm{dL}$ (5.6 $\mathrm{mM}$ ) or previously diagnosed type 2 diabetes [1].

The MS is an increasingly significant global health problem. The National Health and Nutrition Examination Survey 1999-2002 showed that almost $40 \%$ of the U.S. adults were classified as having the MS [2]. The prevalence of MS among Polish adults is estimated at the level of $23 \%$ (men) and $20 \%$ (women) [3].

The MS is believed to be a consequence of a sedentary lifestyle, excessive intake of calories and physical inactivity, although genetic factors are also involved $[4,5]$.

The elevated oxidative stress, increased leptin and decreased adiponectin levels, the activation of inflammatory cytokines and prothrombotic mediators are associated with MS [6, 7]. The reduction of antioxidant enzyme activities and an increase in lipid peroxidation are results of a prolonged state of oxidative stress.

The following study aims to investigate the changes in the plasma membrane of erythrocytes and in the activities of antioxidant enzymes caused by the MS. Alterations in plasma lipid profile and oxidative stress can affect erythrocyte membranes and disturb the structure and function of cell membranes.

\section{Materials and methods}

\section{Patients}

The study involved 75 healthy individuals and 85 patients with MS diagnosed according to IDF definition. The exclusion criteria were as follows: (i) secondary dyslipidemia, (ii) any acute or chronic inflammatory processes, (iii) arterial hypertension, (iv) diabetes mellitus, (v) impaired renal or hepatic function, (vi) treatment with hypolipidemic, hypotensive, anticoagulant drugs, (vii) antioxidant therapy, (viii) abuse of alcohol or smoking cigarettes.

These experiments were conducted in accordance with ethical standards as formulated in Helsinki Declaration of 1975 (revised 1983); consent number 241/06/KB of Commission of Medical Research Ethics of Medical University of Lodz, Poland.

Blood from MS patients was obtained from the Department of Clinical Pharmacology, Medical University of Lodz. The samples from healthy volunteers were provided by the Central Blood Bank of Lodz. Blood was collected with anticoagulant (23 mM citric acid, $45.1 \mathrm{mM}$ trisodium citrate, $45 \mathrm{mM}$ glucose) in 5:1 ratio.

Erythrocytes

Erythrocytes were obtained from blood by centrifugation $\left(600 \times g, 10 \mathrm{~min}, 4^{\circ} \mathrm{C}\right)$ and then washed three times with cold $0.9 \% \mathrm{NaCl}$. They were examined immediately after isolation.

Red cell membrane preparation

Erythrocyte membranes were prepared by the method of Dodge [8] with buffer modification. Erythrocytes were hemolyzed with $20 \mathrm{mM}$ Tris- $\mathrm{HCl}$ buffer, $\mathrm{pH}$ 7.4, supplemented with $1 \mathrm{mM}$ EDTA and $0.01 \%$ PMSF on ice for $15 \mathrm{~min}$. The erythrocyte membranes were centrifuged at $20,000 \times g$ for $5 \mathrm{~min}$. The membranes were washed several times with the above-mentioned buffer until the "white ghost" (hemoglobin-free) state was attained. All buffers were cooled to $4{ }^{\circ} \mathrm{C}$ prior to use and the whole preparation procedure was conducted on ice.

The protein concentration was estimated according to the method of Lowry [9]. The concentration of protein in the sample was read from a calibration curve in the range 50-300 $\mu \mathrm{g}$ proteins/ml using albumin from bovine serum as the standard.

\section{Cholesterol concentration}

The extraction of lipids from erythrocytes was carried out according to the method of Rodriguez-Vico [10] using chloroform/methanol mixture $(2: 1 \mathrm{v} / \mathrm{v})$. The concentration of cholesterol was determined using Liebermann-Burchard reagent [11] and was expressed as milligrams of cholesterol per milliliter of packed cells ( $\mathrm{mg} \mathrm{HC} / \mathrm{ml}$ packed cell).

\section{Peroxidation of lipids}

The peroxidation of lipids was estimated by the measurement of compounds reacting with 2-thiobarbituric acid (TBA) according to the method of Stock and Dormandy [12]. The absorbance was read at $532 \mathrm{~nm}$. The concentration of TBARS was calculated using a millimolar absorption coefficient for malondialdehyde, $\varepsilon=1.5 \times 10^{5} \mathrm{~mol}^{-1} \mathrm{dm}^{3} \mathrm{~cm}^{-1}$. The hemoglobin concentration was determined by Drabkin method [13]. Absorbance was read at $540 \mathrm{~nm}$. The results were expressed as $\mu$ mol TBARS/g Hb.

\section{ATPase activity}

The activity of ATPase was measured by means of the method of Bartosz [14] based on the quantification of orthophosphate released from ATP during the incubation of erythrocyte membranes with medium $\left(1 \mathrm{mmol} / \mathrm{dm}^{3}\right.$ ATP, $10 \mathrm{mmol} / \mathrm{dm}^{3} \mathrm{MgCl}_{2}, 100 \mathrm{mmol} / \mathrm{dm}^{3}$ buffer Tris- $\mathrm{HCl}, \mathrm{pH}$ 7.4 for total ATPase activity and additionally supplemented with $0.1 \mathrm{mmol} / \mathrm{dm}^{3}$ ouabain to verify activity of $\mathrm{Na}^{+} / \mathrm{K}^{+}$ ATPase). The concentration of orthophosphate released from ATP was determined in supernatant by the method of 
van Veldhoven and Mannaerts [15] and was read from a calibration curve in the range of $2-20 \mu \mathrm{M}$ using $\mathrm{KH}_{2} \mathrm{PO}_{4}$ as the standard. The results were expressed as nmol orthophosphate/mg proteins $\times \mathrm{h}$. The activity of $\mathrm{Na}^{+} \mathrm{K}^{+}$ ATPase was quantified as a difference between ouabain treated and non-treated membranes.

\section{Concentration of thiol groups and glutathione level}

The level of thiol groups in erythrocyte membranes and of glutathione (GSH) in erythrocytes was estimated according to the method of Ellman with 5,5'-dithiobis-(2-nitrobenzoic acid) (DTNB). The concentration of $-\mathrm{SH}$ groups was calculated using a milimolar absorption coefficient for 2-nitro5-thiobenzoate $\left(\mathrm{NTB}^{-}\right), \quad \varepsilon_{412}=13.6 \mathrm{mmol}^{-1} \mathrm{dm}^{3} \mathrm{~cm}^{-1}$ [16]. The results were expressed as $\mu \mathrm{mol}-\mathrm{SH} / \mathrm{mg}$ proteins or $\mu \mathrm{mol} \mathrm{GSH} / \mathrm{ml}$ packed cell.

\section{Fluidity of erythrocyte membranes}

The fluidity of erythrocyte membranes was measured by means of fluorescent anisotropy using two fluorescent probes: 1,6-diphenyl-1,3,5-hexatriene (DPH) and 1-[4'-(trimethylammonium)phenyl]-6-phenyl-1,3,5-hexatriene (TMA-DPH). $\mathrm{DPH}$ is localized in hydrophobic region near the center of the bilayer, while TMA-DPH is incorporated into the polar region of the erythrocyte membrane. The increase in fluorescence anisotropy indicates that the membrane becomes more rigid (less fluid) [17].

Fluorescence anisotropy measurements were carried out with an LS-50B fluorescent spectrometer (Perkin-Elmer, UK). The excitation and emission wavelengths were 348 and $426 \mathrm{~nm}$, respectively. The cuvette holder was temperature controlled $\left(37^{\circ} \mathrm{C}\right)$. Erythrocyte membranes were diluted with buffered saline to protein concentration of $100 \mu \mathrm{g} / \mathrm{ml}$. Final concentration of fluorescent probes was $1 \mu \mathrm{mol} / \mathrm{l}$.

The fluorescence anisotropy ( $r$ ) of the samples was calculated by the fluorescence data manager program using the following equation:

$r=\left(I_{\mathrm{Vv}}-G I_{\mathrm{VH}}\right) /\left(I_{\mathrm{VV}}+2 G I_{\mathrm{VH}}\right)$

where $I_{\mathrm{VV}}$ and $I_{\mathrm{VH}}$ were the vertical and horizontal fluorescence intensities, respectively, to the vertical polarization of the excitation light beam. The factor $G=I_{\mathrm{HV}} / I_{\mathrm{HH}}$ corrects the polarizing effects of the monochromator.

\section{Antioxidant enzymes}

Superoxide dismutase (SOD) activity was estimated according to the method of Misra and Fridovich [18] with epinephrine. The result was expressed as $\mathrm{U} / \mathrm{g} \mathrm{Hb}$.
The activity of catalase (CAT) was measured by means of the method of Aebi [19]. CAT activity was expressed as $\mathrm{U} / \mathrm{g} \mathrm{Hb}$.

The glutathione peroxidase (GPx) activity was estimated according to the method of Rice-Evans et al. [20]. The result was expressed as $\mathrm{U} / \mathrm{mg} \mathrm{Hb}$.

Statistical analysis

The results are presented as mean \pm SD. Differences between groups were assessed by an unpaired Student's $t$ test. The statistical analysis was performed using STATISTICA $^{\circledR}$ ver 9.0 PL software (StatSoft Inc., Tulsa, USA).

\section{Results}

The study cohort included 85 patients ( 37 men, 48 women). The control group included 75 healthy volunteers (33 men, 42 women). Patients with MS had significantly higher waist circumference, BMI values, levels of total cholesterol (increase about $21 \%$ ), LDL-C (increased by $23 \%$ ), triglycerides (increased by $267 \%$ ), glucose (increased by $16 \%)$, systolic and diastolic pressure, and significantly lower level of HDL-C (decreased by $26 \%$ ) when compared to healthy controls. Level of CRP did not differ significantly between groups (Table 1).

Patients with MS had significantly higher levels of cholesterol (about $45 \%$ ) in erythrocyte membrane in

Table 1 Characteristics of control group and patients with MS

\begin{tabular}{llll}
\hline Parameter & $\begin{array}{l}\text { Control } \\
\text { group }\end{array}$ & $\begin{array}{l}\text { Patients with } \\
\text { MS }\end{array}$ & $p$ \\
\hline$n$ & 75 & 85 & \\
Age & $50.3 \pm 8.2$ & $55.9 \pm 7.4$ & \\
Men/women & $33 / 42$ & $37 / 48$ & \\
Waist circumference (cm) & $75.7 \pm 10.0$ & $98.1 \pm 18.8$ & 0.001 \\
Body weight (kg) & $67.0 \pm 7.9$ & $90.7 \pm 12.5$ & 0.001 \\
BMI (kg/m $\left.{ }^{2}\right)$ & $24.9 \pm 2.2$ & $30.5 \pm 3.4$ & 0.001 \\
Systolic pressure (mmHg) & $117.2 \pm 11.7$ & $132.7 \pm 7.4$ & 0.001 \\
Diastolic pressure & $71.2 \pm 6.9$ & $79.2 \pm 6.7$ & 0.001 \\
$\quad$ mmHg) & & & \\
hs-CRP (mg/l) & $1.6 \pm 1.4$ & $2.7 \pm 2.3$ & NS \\
Glucose (mg/dl) & $82.3 \pm 9.2$ & $95.7 \pm 10.5$ & 0.001 \\
Total cholesterol (mg/dl) & $199.5 \pm 24.5$ & $242.2 \pm 36.8$ & 0.001 \\
LDL-C (mg/dl) & $120.7 \pm 19.8$ & $148.8 \pm 35.2$ & 0.01 \\
HDL-C (mg/dl) & $58.7 \pm 10.8$ & $43.8 \pm 9.8$ & 0.001 \\
TG (mg/dl) & $96.5 \pm 29.4$ & $258.2 \pm 94.9$ & 0.001 \\
\hline
\end{tabular}

$h s$ - $C R P$ high sensitivity C-reactive protein, $L D L-C$ low density lipoprotein cholesterol, $H D L-C$ high density lipoprotein cholesterol, $T G$ triglycerides, $N S$ non-statistical significant 
comparison to healthy controls (Table 2). The increase in cholesterol concentration in plasma, especially LDL-C, led to increase in the accumulation of cholesterol in erythrocyte membrane.

In erythrocytes from MS patients, higher level of lipid peroxidation (about $37 \%$ ) in comparison to healthy controls was observed (Table 2). This might be a consequence of the increase in the level of oxidants caused by redox imbalance in cells.

Patients with MS demonstrated substantially lower membrane fluidity (about $10 \%$ higher fluorescent anisotropy values for both probes) than the control group (Table 2). Membrane fluidity depends on the composition of lipids and proteins. Higher level of cholesterol decreases membrane fluidity, especially in polar region of the monolayer. Lipid peroxidation also disturbs membrane fluidity. Incorporation of polar group (ketone, aldehyde, hydroxyl, superoxide) to double bond in the hydrophobic region leads to impairment of the structure of membrane and affects other parameters.

The concentration of thiol groups in erythrocyte membrane observed for patients with MS was significantly lower (about $16 \%$ ) than in the control group (Table 3). The altered level of thiol groups may be a result of the modification of protein conformation or directly damage caused by free radicals. The decrease in total ATPase activity $(8.4 \%)$ and $\mathrm{Na}^{+} \mathrm{K}^{+}$ATPase activity $(26 \%)$ was observed in erythrocytes from MS patients in comparison with the control group (Table 3). Lower activity of ATPase may be caused by change in membrane viscosity (fluidity) or by direct protein damage by free radicals or other products emerging during lipid peroxidation.

The activity of GPx for patients with MS was significantly lower $(13 \%)$ than that observed in the control group. No significant changes in activities of SOD or CAT were observed. The concentration of GSH was significantly lower $(8 \%)$ in patients with MS in comparison to the control group (Table 4).

Higher level of lipid peroxidation and lower activity of GPx may suggest that patients with MS demonstrate higher level of oxidative stress than the control group.

\section{Discussion}

The oxidative stress plays an important role in dysfunction of endothelial pathogenesis, hypertension, inflammation conditions, atherosclerosis [21], hypercholesterolemia [22], and diabetes [23]. An intensification of oxidative stress in patients with MS was previously reported [24]. Shim et al. [25] observed an important growth in the number of neutrophils, lymphocytes, monocytes, and eosinophils, which generate a large amount of reactive oxygen species (ROS) after stimulation in patients with MS. As a result of higher generation of ROS, the damage of lipids, proteins, and nucleic acids is observed in cells. Mittal and Kant [26] observed an increase of concentration of malondialdehyde in erythrocytes from postmenopausal woman suffering from obesity, which directly correlates with body mass index. An increase in the concentration of TBARS and conjugated dienes in erythrocytes derived from patients diagnosed with type-2 hypercholesterolemia was reported [22]. Plasma membrane lipids are documented to be the major targets for ROS in erythrocytes. In this study, the level of lipid peroxidation (TBARS) was significantly higher in erythrocytes from patients with MS in comparison to the control group. This result suggests disturbance of pro- and antioxidant balance.

The major disturbance in MS is an abnormal lipid metabolism: elevated plasma triglycerides, increased level of LDL, and decreased level of HDL. The altered

Table 2 Cholesterol concentration, level of lipid peroxidation and membrane fluidity in erythrocytes for control and MS patients groups

\begin{tabular}{|c|c|c|c|}
\hline Parameter & Control group & MS patients & $p$ \\
\hline Total cholesterol content (mg CH/ml packed cell) & $2.82 \pm 0.64(n=56)$ & $4.09 \pm 1.19(n=80)$ & 0.001 \\
\hline Lipid peroxidation ( $\mu$ mol TBARS/g Hb) & $0.329 \pm 0.078(n=73)$ & $0.453 \pm 0.140(n=82)$ & 0.001 \\
\hline TMA-DPH fluorescent anisotropy (r) & $0.308 \pm 0.019(n=22)$ & $0.339 \pm 0.047(n=28)$ & 0.01 \\
\hline DPH fluorescent anisotropy (r) & $0.271 \pm 0.022(n=22)$ & $0.297 \pm 0.032(n=28)$ & 0.005 \\
\hline
\end{tabular}

Table 3 Thiol groups and ATPase activity in erythrocyte for control and MS patient groups

\begin{tabular}{lccc}
\hline Parameter & Control group & MS patients & $p$ \\
\hline Total thiol groups content $(\mathrm{nmol}-\mathrm{SH} / \mathrm{mg}$ proteins) & $81 \pm 25(n=34)$ & $68 \pm 20(n=78)$ \\
Total ATPase activity $(\mathrm{nmol} \mathrm{Pi/mg} \mathrm{protein} \times \mathrm{h})$ & $536.8 \pm 134.5(n=52)$ & $491.6 \pm 116.8(n=70)$ \\
$\mathrm{Na}^{+}, \mathrm{K}^{+}$ATPase activity $(\mathrm{nmol} \mathrm{Pi/mg} \mathrm{protein} \times \mathrm{h})$ & $249.5 \pm 86.7(n=52)$ & $185.0 \pm 68.5(n=70)$ & 0.01 \\
\hline
\end{tabular}


Table 4 Level of GSH and activities of antioxidant enzymes in control and MS patient groups

\begin{tabular}{|c|c|c|c|}
\hline Parameter & Control group & MS patients & $p$ \\
\hline GSH concentration $\mu \mathrm{mol} \mathrm{GSH} / \mathrm{ml}$ packed cell & $1.37 \pm 0.37(n=75)$ & $1.26 \pm 0.29(n=74)$ & 0.05 \\
\hline Glutathione peroxidase (GPx) activity $\mathrm{U} / \mathrm{g} \mathrm{Hb}$ & $20.91 \pm 4.65(n=65)$ & $18.25 \pm 4.72(n=82)$ & 0.001 \\
\hline Catalase (CAT) activity U/mg $\mathrm{Hb}$ & $261.1 \pm 64.2(n=70)$ & $261.6 \pm 60.3(n=80)$ & NS \\
\hline Superoxide dismutase (SOD) activity U/g Hb & $2856 \pm 644(n=73)$ & $2770 \pm 621(n=82)$ & NS \\
\hline
\end{tabular}

NS Non-statistical significant

membrane microviscosity reflects the changes of membrane lipid composition resulting from intensive exchange between circulating and membrane lipids, as well as from abnormal cellular lipid synthesis and metabolism [27]. The LDL of blood plasma was capable of exchanging the cholesterol with erythrocyte membranes [28]. The concentration of total cholesterol in erythrocytes, derived from MS patients, was significantly higher when compared to that of the control group. These results confirm data obtained for erythrocytes from patients with hypercholesterolemia $[22,29]$. Hypercholesterolemic people demonstrate a higher erythrocyte membrane cholesterol/ phospholipid ratio. This alteration of the lipid membrane correlates inversely with the plasma concentration of HDLcholesterol [30]. The higher level of cholesterol, especially higher level of LDL-C, and raised production of ROS may lead to intensification of atherosclerosis processes.

Changes in cholesterol content and level of lipid peroxidation affect the membrane fluidity. The decrease in plasma membrane fluidity was observed as a result of the increase in the concentration of cholesterol in plasma membrane [31]. A significant drop in membrane fluidity in erythrocytes from patients with type-2 hyperlipidemia together with the increase in cholesterol concentration was previously reported [22]. In this study, the increase in fluorescent anisotropy for both fluorescent probes indicates the decrease in fluidity of plasma membrane in hydrophilic and hydrophobic regions. The decrease in membrane fluidity may further lead to the decrease in the ability of erythrocytes to change shape and finally to disorder of the blood flow.

The membrane lipid composition and elevated oxidative stress may contribute to the changes in the activity of the main membrane enzymes. A higher cholesterol concentration in the membrane was documented to decrease activities of $\mathrm{Ca}^{2+} \mathrm{Mg}^{2+}$ ATPase and $\mathrm{Na}^{+} \mathrm{K}^{+}$ATPase, and disturbs ion transport $[32,33]$. The activity of $\mathrm{Na}^{+} \mathrm{K}^{+}$ ATPase diminished in persons with familial hypercholesterolemia [21]. The decrease in $\mathrm{Na}^{+} \mathrm{K}^{+}$ATPase activity can be also associated with diabetes [34]. The reactive form of oxygen, nitrogen, and chlorine may modify membrane protein and may inhibit enzymes, including ATPases [35, 36]. Also products of lipid peroxidation might contribute to disturbance of ATPase activity. In the present study, both the total ATPase and $\mathrm{Na}^{+} \mathrm{K}^{+}$ATPase activities decreased in comparison to those in the control group. The decrease in $\mathrm{Na}^{+} \mathrm{K}^{+}$ATPase activity disturbs not only transport of $\mathrm{Na}^{+}$and $\mathrm{K}^{+}$ions across membrane, but also can modify resting potential of membrane and volume of cell. In addition, $\mathrm{Na}^{+}$gradient is also used as a source of energy by certain carrier processes, e.g., $\mathrm{Na}^{+}$glucose symport. The decrease in $\mathrm{Na}^{+} \mathrm{K}^{+}$ATPase activity may therefore lead to the development of cardiovascular complications.

GSH plays a key role in cellular homeostasis. It is a major factor in regulation of cell life, proliferation, and death. GSH was also involved in cell defense against prooxidants, both directly as low-weight antioxidants and as a cofactor for GPx. In the present study, the decrease in GSH concentration was observed. Substantial decrease in the GSH concentration and the increase in GSSG/GSH ratio in patients with hypertension, dyslipidemia, MS, and obesity were reported $[37,38]$. Similar changes in plasma from patients with type 2 diabetes were also noticed [39].

The decrease in concentration of thiol groups in erythrocytes membranes from type-2 hypercholesterolemic patients was reported earlier [22]. Thiol groups play an important role in folding and stability of proteins, including enzymes, and in the modulation of a variety of activities of the cell membrane, including transport processes across the membrane. Thiol groups from membrane proteins are liable to modifications caused by oxidants or alkyl agent. Changes in level of thiol groups are a result of the oxidative damage to membrane proteins or changes in structure of proteins. In this study, patients with MS demonstrated lowered contents of proteins thiol groups compared to the healthy group.

The antioxidant enzymes are major parts of cell defense against ROS. In the present research, the GPx activity was significantly decreased, while activities of CAT or SOD were similar to those in the healthy group. Karaouzen et al. [40] found correlation between activities of antioxidant enzymes and aging in healthy and obese men. Activities of SOD, CAT, and GPx were higher in healthy young men when compared to those in older men. Activities of SOD and CAT were enhanced in obese young men and reduced 
in older men, and activity of GPx was lower in both groups. Mansengo et al. [38] documented lower activities of CAT and GPx in patients with hypercholesterolemia and hypertension, while activity of SOD was only reduced in patients with hypertension. Cardona et al. [37] noticed the increase in CAT activity and the decrease in GPx activity in patients with hypertriglyceridemia, regardless of MS. Also Cardona et al. [41] observed the decrease in GPx activity, but no changes in activities of SOD or CAT in blood from patients with MS were observed when compared to those in the control group. It seems that activities of antioxidant enzymes depend on age of subjects, tissue, associated illness, and dietary habit.

\section{Conclusions}

The above-presented results point to some essential changes in the erythrocyte plasma membranes. The following changes occur in plasma membrane lipids: the increase in cholesterol concentration and in levels of lipid peroxidation as well as the decrease in plasma membrane fluidity. Collected data also demonstrate changes in functions of plasma membrane proteins: the decrease in concentration of thiol groups and the inhibition of ATPase activity.

Antioxidant enzymes represent an important part of the antioxidant defense system of aerobic cells. The decrease in antioxidant levels and increase in lipid peroxidation resulted in oxidative stress in blood of patients with MS.

The MS is not a disease in the strict sense of this word. It is a metabolic disorder which has multi-factor pathology. Changes observed in erythrocytes occur as a result of all disorders connected to abnormal metabolism of lipids, diabetes and hypertension.

Acknowledgments This study was supported by the University of Lodz, Grant 506/982, and by the Medical University of Lodz, Grant 503-5006-3.

Open Access This article is distributed under the terms of the Creative Commons Attribution License which permits any use, distribution, and reproduction in any medium, provided the original author(s) and the source are credited.

\section{References}

1. IDF worldwide definition of the metabolic syndrome (2006). Available www.idf.org/metabolic-syndrome

2. Ford ES (2005) Prevalence of the metabolic syndrome defined by the International Diabetes Federation among adults in the U.S. Diabetes Care 28:2745-2749

3. Wyrzykowski B, Zdrojewski T, Sygnowska E, Biela U, Drygas W, Tykarski A, Kozakiewicz K, Broda G (2005) Epidemiology of metabolic syndrome in Poland. Results of program WOBASZ
[Epidemiologia zespołu metabolicznego w Polsce. Wyniki programu WOBASZ]. Kardiologia Polska 63:6(Suppl 4)

4. Groop L (2000) Genetics of the metabolic syndrome. Br J Nutr 83:S39-S48

5. Poulsen P, Vaag A, Kyvik K, Beck-Nielsen H (2001) Genetic versus environmental etiology of the metabolic syndrome among male and female twins. Diabetologia 44:537-543

6. Ohni M (2006) Inflammatory cytokines in metabolic syndrome (MS) a comparison between MS and simple obesity. XIV Symposium on atherosclerosis, Rome, We-P13:322

7. Saely CH, Risch L, Hoefle G, Rein P, Muendlein A, Marte T, Aczel S, Langer P, Drexel H (2007) Low serum adiponectin is independently associated with both the metabolic syndrome and angiographically determined coronary atherosclerosis. Clin Chim Acta 383:97-102

8. Dodge JT, Mitchell C, Hanahan DJ (1963) The preparation and chemical characteristics of hemoglobin-free ghosts of human erythrocytes. Arch Biochem Biophys 100:119-130

9. Lowry OH, Rosenbrough NJ, Farr AL, Randall RJ (1951) Protein measurement with the Folin phenol reagent. J Biol Chem 193:265-275

10. Rodriguez-Vico F, Martinez-Caynela M, Zafra MF, GarciePeregin F, Ramirez H (1991) A procedure for the simultaneous determination of lipid and protein in biomembranes and other biological samples. Lipids 26:77-80

11. Kim E, Goldberg M (1969) Serum cholesterol assay using a stable Liebermann-Burchard reagent. Clin Chem 12:1171-1179

12. Stocks J, Dormandy TL (1971) The autooxidation of red cell lipids induced by hydrogen peroxide. Br J Haematol 20:95-111

13. Drabkin DL (1946) The crystallographic and optical properties of the hemoglobin of men in comparison with those of other species. J Biol Chem 164:703-723

14. Bartosz G, Bartosz M, Sokal A, Gebicki JM (1994) Stimulation of erythrocyte membrane $\mathrm{Mg}^{2+}$-ATPase by membrane disturbing agents. Biochem Mol Biol Int 34:521-529

15. Van Veldhoven PP, Mannaeters GP (1994) Inorganic and organic phosphate measurements in the nanomolar range. Anal Biochem $161: 45-48$

16. Ellman G (1959) Tissue sulfhydryl groups. Arch Biochem Biophys 82:70-77

17. Zavodnik IB, Piasecka A, Szosland K, Bryszewska M (1997) Human red blood cell membrane potential and fluidity in glucose solutions. Scand J Clin Lab Invest 57:59-63

18. Misra HP, Fridrovich I (1972) The generation of superoxide radical during autooxidation of hemoglobin. J Biol Chem 247:6960-6962

19. Aebi H (1984) Catalase in vitro. Methods Enzymol 105:121-126

20. Rice-Evans CA, Diplock AT, Symons MCR (1991) Techniques in free radicals research, vol 22. Elsevier, New York, pp 194-196

21. Roberts CK, Barnard RJ, Sindhu RK, Jurczak M, Ehdaie A, Vaziri ND (2006) Oxidative stress and dysregulation of $\mathrm{NAD}(\mathrm{P}) \mathrm{H}$ oxidase and antioxidant enzymes in diet-induced metabolic syndrome. Metabolism 55:928-934

22. Koter M, Franiak I, Strychalska K, Broncel M, ChojnowskaJezierska J (2004) Damage to the structure of erythrocyte plasma membranes in patients with type-2 hypercholesterolemia. Int $\mathbf{J}$ Biochem Cell Biol 36:205-215

23. Ramazan M (2004) Levels of ceruloplasmin, transferrin, and lipid peroxidation in the serum of patients with type 2 diabetes mellitus. J Diabetes 18:193-197

24. Ferder L, Inserra F, Martínez-Maldonado M (2006) Inflammation and the metabolic syndrome: role of angiotensin II and oxidative stress. Curr Hypertens Rep 8:191-198

25. Shim W, Kim H, Kang E, Ahn C, Lim S, Lee H, Cha B (2006) The association of total and differential white blood cell count 
with metabolic syndrome in type 2 diabetic patients. Diabetes Res Clin Prac 73:284-291

26. Mittal P, Kant R (2009) Correlation of increased oxidative stress to body weight in disease-free post menopausal women. Clin Biochem 42:1007-1011

27. Zicha J, Kunes J, Devynck MA (1999) Abnormalities of membrane function and lipid metabolism in hypertension. Am J Hypertens 12:315-331

28. Gottlieb M (1980) Rates of cholesterol exchange between human erythrocytes and plasma lipoproteins. Biochim Biophys Acta 600:530-541

29. Broncel M, Cieślak D, Koter-Michalak M, Duchnowicz P, Mackiewicz K, Chojnowska-Jezierska J (2006) The anti-inflammatory and antioxidants effects of micronized fenofibrate in patients with visceral obesity and dyslipidemia. Pol Merkur Lekarski 119:547-550

30. Martínez M, Vayá A, Gil L, Martí R, Dalmau J, Aznar J (1998) The cholesterol/phospholipid ratio of the erythrocyte membrane in children with familial hypercholesterolemia. Its relationship with plasma lipids and red blood cell aggregability. Clin Hemorheol Microcirc 18:259-263

31. Chabanel A, Flamm M, Sung KLP, Lee MM, Schachter D, Chien S (1983) Influence of cholesterol content on red cell membrane viscoelasticity and fluidity. Biophys J 44:171-176

32. Bastiaanse LEM, Höld KM, Van der Laarse A (1997) The effect of membrane cholesterol content on ion transport processes in plasma membranes. Cardiovasc Res 33:272-283

33. Odbayar TO, Badamhand D, Kimura T, Takashi Y, Tsushida T, Ide T (2006) Comparative studies of some phenolic compounds (quercetin, rutin, and ferulic acid) affecting hepatic fatty acid synthesis in mice. J Agric Food Chem 54:8261-8265

34. Rabini RA, Galassi R, Fumelli P, Dousset N, Solera ML, Valdiguie P, Curatola G, Ferretti G, Taus M, Mazzanti L (1994) Reduced
$\mathrm{Na}^{+} \mathrm{K}^{+}$ATPase activity and plasma lysophosphatidylcholine concentration in diabetic patients. Diabetes 43:915-919

35. Kaplan P, Babusikova E, Lehotsky J, Dobrota D (2003) Free radical-induced protein modification and inhibition of $\mathrm{Ca}^{2+}$. ATPase of cardiac sarcoplasmic reticulum. Mol Cell Biochem 248:41-47

36. Siems W, Capuozzo E, Lucano A, Salerno C, Crifò C (2003) High sensitivity of plasma membrane ion transport ATPases from human neutrophils towards 4-hydroxy-2,3-trans-nonenal. Life Sci 73:2583-2590

37. Cardona F, Tunez I, Tasset I, Murri M, Tinahones F (2008) Similar increase in oxidative stress after fat overload in persons with baseline hypertriglyceridemia with or without the metabolic syndrome. Clin Biochem 41:701-705

38. Mansengo ML, Redon J, Martinez-Hervas S, Real JT, Martinez F, Blesa S, Gonzalez-Albert V, Saez GT, Carmena R, Chaves F (2011) Different impacts of cardiovascular risk factor on oxidative stress. Int J Mol Sci 12:6146-6163

39. Calabrese V, Cornelius C, Koverech G, Trovato A, Ventimiglia B, Cavallaro M, Scuto M, Rizza S, Zanoli L, Neri S, Castellino P (2012) Oxidative stress, glutathione status, sirtuin and cellular stress response in type 2 diabetes. Biochim Biophys Acta 1822:729-736

40. Karaouzen N, Merzouk H, Aribi M, Merzouk SA, Yahia Berrouiguet A, Tessier C, Narce M (2011) Effects of the association of aging and obesity on lipids, lipoproteins and oxidative stress biomarkers: a comparison of older with young men. Nutr Metab Cardiovasc Dis 21:792-799

41. Cardona F, Túnez I, Tasse I, Montilla P, Collantes E, Tinahones FJ (2008) Fat overload aggravates oxidative stress in patients with the metabolic syndrome. Eur J Clin Invest 38:510-515 